\title{
Mindfulness in Schools: a Health Promotion Approach to Improving Adolescent Mental Health
}

\author{
Supakyada Sapthiang ${ }^{1} \cdot$ William Van Gordon $^{2}$ (D) $\cdot$ Edo Shonin $^{3}$ \\ Published online: 16 October 2018 \\ (C) The Author(s) 2018
}

\begin{abstract}
Between 10 and $20 \%$ of adolescents worldwide experience a mental health problem within a given 12-month period. Mental health problems impact on an adolescent's potential to live a fulfilling and productive life and lead to challenges such as stigma, isolation and discrimination. To address this need, in recent years, there has been growing interest into broad-based school-integrated health promotion interventions that seek to build resilience and augment protective factors in adolescents. Mindfulness-based interventions (MBIs) reflect one such approach that have been administered to adolescent populations in both resilience building and treatment contexts. This paper discusses the utility of school-based MBIs as an adolescent health promotion approach and makes recommendations for intervention design, delivery and evaluation. Emerging evidence indicates that school-integrated MBIs may be a cost-effective means of not only meeting government objectives relating to adolescent mental health, but also for improving the wellbeing of teachers and parents. Furthermore, there is growing evidence indicating that mindfulness can elicit improvements in student learning performance and general classroom behaviour. However, notwithstanding these beneficial properties, there remains a need to conduct large-scale empirical investigations that seek to evaluate the effectiveness of school-integrated MBIs at a regional or national level. A further challenge is the need to ensure that mindfulness instructors are able to impart to adolescents an experiential understanding of this ancient contemplative technique.
\end{abstract}

Keywords Mindfulness $\cdot$ Health promotion $\cdot$ Adolescent mental health $\cdot$ School-based interventions

William Van Gordon

w.vangordon@derby.ac.uk

Supakyada Sapthiang

ss18600@essex.ac.uk

Edo Shonin

e.shonin@awaketowisdom.co.uk

Back Affiliation 
Between 10 and $20 \%$ of adolescents (typically defined as individuals aged 10-18 years) worldwide experience a mental health problem within a given 12-month period (Kieling et al. 2011). The average age of onset for mental illness is 12-24 years, with 50\% of all mental illness having commenced before the age of 14 (World Health Organization [WHO] n.d.). Anxiety disorders and mood disorders reflect the most prevalent psychiatric issues in adolescents, with depression being strongly related to suicide completion (WHO 2012). Mental illness in adolescents is linked to more serious psychiatric problems in adulthood as well as (for example) academic underachievement, delinquency and criminogenic behaviour, impaired employment prospects, financial problems and participating in risk-taking behaviour (Derevensky and Gupta 2004; Dowling et al. 2017; Dray et al. 2017; Granero et al. 2014; Grant et al. 2010). Conversely, mental wellbeing in adolescence aids in the development of healthy functioning adults that can make meaningful contributions to the socioeconomic development of a country (WHO 2012).

Key determinants of mental illness in adolescents include (but are not limited to) low socioeconomic status, social isolation, exposure to violence and lack of peer or family support (WHO 2012). However, the impact of such determinants can be mitigated by protective factors such as family and community cohesion, pro-social behaviour and social connectedness, support from schools and mental health services (including social services), and the community's engagement with local and national health promotion schemes (e.g. asset-based community development and social prescribing initiatives) (Dray et al. 2017; WHO 2012).

In line with Rose's (1992) prevention paradox principle (i.e. where it is deemed that blanket prevention initiatives that incorporate low-risk individuals can reduce disease burden more effectively than targeting only high-risk cases), in recent years, there has been growing interest into broad-based adolescent mental health promotion interventions that seek to build resilience and augment protective factors (Windle 2011). While such approaches have been delivered in homeless shelters, juvenile detention centres and outpatient clinics, they are typically delivered as school-based projects-whether as curriculum-integrated courses or structured extracurricular activities (Bluth et al. 2016; Dray et al. 2017; Weisz et al. 2005).

One such adolescence resilience-building approach that has been evaluated empirically is the US-based 12-week PENN Resiliency Program that employs cognitive behavioural principles to augment intra-psychic and interpersonal protective factors as part of school curriculumintegrated group sessions (Gillham et al. 2008). The PENN Resiliency Program has demonstrated some efficacy for improving resilience in adolescent levels of depression and problem internalisation, but the effects on these specific outcomes have not been replicated across successive meta-analyses (Bastounis et al. 2016; Brunwasser et al. 2009). A more recent metaanalysis, focussing on a broad range of both children and adolescent resilience programmes (i.e. not limited to the PENN Resiliency Program), evaluated the effects of 57 ( $n=41,527)$ controlled school-based resiliency studies that focussed on augmenting protective factors such as cognitive competence, coping ability, problem solving capacity and communication skills (Dray et al. 2017). The resiliency interventions were mostly based on cognitive behaviour therapy (CBT) yet despite showing a significant effect for reduction of anxiety and general psychological distress in children (i.e. individuals aged under 10 years), these effects were not observed for adolescents (Dray et al. 2017).

This observation appears to be consistent with the wider scientific and clinical consensus relating to the applications of CBT that, while demonstrably efficacious for a range of psychological issues, can yield high rates of relapse and/or non-completion amongst some population (including adolescent) groups (Shonin et al. 2014a). Indeed, the selective efficacy 
of second-wave cognitive behavioural approaches such as CBT was a factor that resulted in a marked growth of interest and empirical investigation into third-wave cognitive behavioural approaches. Unlike 'second-wave' cognitive behavioural approaches that seek to modify core beliefs and faulty thinking patterns, third-wave CBT approaches, such as mindfulness-based interventions (MBIs), advocate the acceptance of distressing psychological and somatic stimuli as part of a perceptual strategy to maintain awareness of present moment experiences (Shonin et al. 2012).

Mindfulness is a form of meditation that derives from Buddhist practice (Van Gordon et al. 2016). It corresponds to the 'process of engaging a full, direct, and active awareness of experienced phenomena that is: (i) psycho-spiritual in aspect, and (ii) maintained from one moment to the next' (Van Gordon et al. 2015, p. 592). Mindfulness interventions have been administered to adolescent populations in both resilience building and treatment contexts, including as part of large-scale health promotion initiatives. For example, in treatment contexts, findings demonstrate that mindfulness can lead to improvements in adolescents' levels of (but not limited to) (i) anxiety and depression (Zoogman et al. 2014), (ii) rumination, hostility, negative coping, intrusive thoughts, emotional arousal and stress in interpersonal relationships (Sibinga et al. 2013), (iii) co-occurring post-traumatic stress and substance use disorder (Fortuna et al. 2018) and (iv) diabetes (Shomaker et al. 2017). Findings likewise demonstrate that mindfulness can be an effective means for building resilience via improvements in (for example) healthy lifestyle behaviours such as physical exercise (SalmoiragoBlotcher et al. 2018); working memory capacity (Quach et al. 2016); emotional wellbeing (Galla 2016); optimism and social competent behaviours (Schonert-Reichl and Lawlor 2010); and self-compassion, perceived stress and life satisfaction (Bluth et al. 2015).

\section{Mechanisms of Action}

In addition to the aforementioned empirical findings, support for the implementation of broadbased resilience-building approaches in adolescents derives from psychological models such as problem behaviour theory (Donovan et al. 1991) and ontological addiction theory (Shonin et al. 2016; Van Gordon et al. 2018). These models assert that a given problematic behaviour or mental illness symptom is invariably an indicator of a more systemic maladaptive belief or unmet psychosocial need, which can manifest across multiple risk-taking behaviours or psychopathologies. Indeed, adolescents often develop destructive cognitive or behavioural strategies (e.g. thought rumination, self-blame, violence and aggression, substance and alcohol abuse, problem gambling) as a floored means of coping with distressing feelings or situations (Canale et al. 2016). Furthermore, emotions are often experienced with greater frequency and intensity in adolescence due to cognitive and biological (including sexual) maturation, as well as the growing importance of interpersonal interactions and peer acceptance (Agarwal and Dixit 2017).

Accordingly, it appears that a key mechanism of action of mindfulness is to create 'mental breathing space' such that adolescents can not only start to observe their thoughts and feelings, but can also learn to remain 'unattached' to them by relating to them as 'passing phenomena' (Shonin et al. 2012). In turn, this greater awareness and perceptual distance from thoughts, feelings and sensory processes fosters a greater capacity to regulate emotions during the developmentally demanding period of adolescence (Agarwal and Dixit 2017). In this manner, learning to apply mindfulness techniques during adolescence can promote healthy character 
and personality formation, as well as cultivate resilience and coping skills that continue to have utility during adulthood (Agarwal and Dixit 2017).

\section{Intervention Design and Delivery}

While advocates of broad-based resilience-building adolescent interventions frequently cite schools as an optimum delivery setting, they also highlight the importance of tailoring such interventions to the needs of young people as well as seeking to augment protective factors such as involving parents and other community support infrastructure (Dowling et al. 2017). In respect of mindfulness interventions, more specific recommendations for school-based implementation typically include maximising the efficacy and acceptability of MBIs by (1) using or creating a physical space where young people feel safe, (2) involving school personnel in a supporting capacity, (3) planning out-of-class (online or face-to-face) interaction between adolescents and the programme facilitator to cultivate trust and (4) making minor curriculum adjustments as required to meet the specific needs of the adolescent group in question (i.e. without any material deviations from the intervention protocol) (Bluth et al. 2016).

More technically orientated adolescent-focussed recommendations by Shonin et al. (2014b) also advocate (i) the use of meditative anchors to help young people overcome concentration difficulties (e.g. counting the breath from 1 to 10), (ii) guiding meditations (e.g. by using gently spoken phrases such as 'breathing in, I am fully aware of my in-breath' and 'breathing out, I am fully aware of my out-breath'), (iii) not forcing the breathing (i.e. young people should allow the breath to follow its natural course), (iv) making use of age-appropriate metaphors (e.g. mindfulness can be likened to the sun that causes flowers to grow by simply observing and shining on them, or cats that tend to be more deliberate and composed in their movements compared to dogs), (v) ensuring course leaders are adequately trained and teach mindfulness from an experiential perspective (i.e. so that instructors "naturally exert a reassuring presence that helps schoolchildren to relax and connect with their own capacity for cultivating meditative awareness', p.31), (vi) supporting young people to integrate mindfulness into everyday life situations (e.g. encouraging at-home mindfulness practice by providing a $\mathrm{CD}$ of guided meditations and inviting parents, caregivers and relevant community figures to partake in mindfulness practices with young people outside school), (vii) making use of mindfulness reminders (e.g. by guiding adolescents to apply the three-step SOS technique at the point disruptive thought or feelings arise: (1) Stop, (2) Observe the breath and (3) Step back and watch the mind), (viii) teaching adolescents to adopt a correct meditation posture (i.e. that is stable and upright but at the same time natural and relaxed), (ix) making mindfulness practice enjoyable and stimulating for young people (e.g. using sensory aids such as a meditation singing bowl or practicing mindfulness in nature) and ( $\mathrm{x}$ ) inviting both students and school teachers to assume the role of 'mindfulness champions' as a means of enhancing engagement.

The present authors would also recommend basing the intervention on a student mindfulness approach that has already been validated empirically. Examples include programmes such as Learning to BREATHE (Broderick 2013), '.b' (pronounced 'Dot be') Mindfulness in Schools curriculum (Kuyken et al. 2013), Mindfulness Education programme (SchonertReichl and Lawlor 2010) and Meditation Awareness Training (used with lightly older student groups; Van Gordon et al. 2014). Typically, such programmes deliver mindfulness in 
group sessions and comprise weekly taught sessions with guided mindfulness activities and an at-home practice element (Shonin et al. 2012). Given the efficacy of MBIs appears not to be undermined by teaching mindfulness over the internet (e.g. Jayawardene et al. 2017), coordinating the delivery of MBIs to schools via the internet may be an attractive proposition for adolescent wellbeing stakeholders as it would help to minimise the impact on costs and school resources.

\section{Key Performance Indicators and Evaluating Effectiveness}

Key performance indicators (KPIs) for health promotion school-based MBI initiatives should seek to align with local and national policies relating to young people's health, wellbeing and education. For example, in the UK, such key national policies include Closing the Gap: Priorities for Essential Change in Mental Health, Future in Mind and The Five Year Forward View for Mental Health. While the primary KPIs are thus likely to be linked to promotion, prevention and early intervention, examples of other relevant KPIs - which allow a gauge of the wider impact of school-based MBIs - might be linked to assessing (i) the number of adolescents who completed mindfulness training within the project timescales, (ii) the number of schools involved in programme delivery, (iii) levels of non-completion amongst students who commence mindfulness training, (iv) improvements in school teachers' and parents' mental health and wellbeing (i.e. as a result of either directly receiving mindfulness training themselves if connected with the project or due to the indirect benefits resulting from improvements in adolescent levels of wellbeing and/or behaviour), (v) improvements in student levels of school attendance, (vi) improvements in student behaviour, (vii) improvements in student learning performance and cognitive functioning (e.g. attention and executive memory function), (viii) maintenance of primary outcome measures (i.e. health, wellbeing and resilience) at (for example) 12 months following programme completion, (ix) maintenance of mindfulness practice (including maintenance of mindfulness practice support infrastructure) at (for example) 12 months following programme completion and (x) the total cost per participant.

Many of the abovementioned KPIs could be adequately and efficiently assessed using psychometrically well-established scales such as the Stirling Children's Wellbeing Scale (including resiliency subscales; Liddle and Carter 2015) and the Mindful Attention Awareness Scale for Adolescents (MAAS-A; Brown et al. 2011). For resilience building interventions, the MAAS-A might be more suitable than adolescent mindfulness measures such as the Child and Adolescent Mindfulness Measure (Kuby et al. 2015), as it has been shown to have good psychometric properties for both healthy and psychiatric adolescent populations. KPIs relating to school attendance and behaviour could be assessed via school records (e.g. days absent and behaviour warnings and/or detention records) and changes in student learning performance, and cognitive functioning might be assessed using (for example) the Behaviour Rating Inventory of Executive Functioning (Gioia et al. 2000).

\section{Conclusions and Further Considerations}

Adolescents with mental health issues experience a number of challenges including stigma, isolation and discrimination. These issues often impact on educational attainment and the 
potential to live a fulfilling and productive life (WHO n.d.). In line with the prevention paradox principal, there is growing interest into the roles of broad-based school-integrated health promotion interventions that seek to target a range of resiliency and protective factors in adolescents. Mindfulness reflects one such resiliency-building approach that has been shown to be efficacious in adolescent research studies for cultivating a range of psychological adjustment and coping strategies, as well as directly treating adolescent psychopathology (Agarwal and Dixit 2017; Shonin et al. 2012).

Emerging evidence indicates that school-based mindfulness resiliency approaches may be a cost-effective means of not only meeting government objectives relating to adolescent mental health, but also for improving the wellbeing of teachers and parents. Furthermore, there is growing evidence indicating that mindfulness can elicit improvements in student learning performance and general classroom behaviour (Shonin et al. 2012). The fact that it appears mindfulness can also be delivered in an efficacious manner as an internet-mediated intervention further increases its appeal given the cost-effectiveness of this delivery mode. However, notwithstanding these beneficial facets, there remains a need to conduct large-scale empirical investigations that seek to evaluate the effectiveness of school-integrated MBIs at a regional or national level. Furthermore, based on issues arising during the implementation of mindfulness in other applied settings, a further challenge that will likely arise relates to the difficulty in training or identifying a sufficient number of skilled mindfulness teachers. Indeed, according to Van Gordon et al. (2017), one of the most important factors relating to the effectiveness of mindfulness approaches is not the design, scale or delivery method of a given intervention, but the extent to which the mindfulness instructor is 'soaked in meditation' and can thus transmit an experiential understanding of this ancient contemplative technique.

Author Contributions All authors were involved in the conception and writing of the paper. Furthermore, we confirm that all authors are responsible for all contents of the article and had authority over manuscript preparation and the decision to submit the manuscript for publication.

\section{Compliance with Ethical Standards}

Conflict of Interest The authors declare that they have no conflict of interest.

Open Access This article is distributed under the terms of the Creative Commons Attribution 4.0 International License (http:/creativecommons.org/licenses/by/4.0/), which permits unrestricted use, distribution, and reproduction in any medium, provided you give appropriate credit to the original author(s) and the source, provide a link to the Creative Commons license, and indicate if changes were made.

\section{References}

Agarwal, A., \& Dixit, V. (2017). The role of meditation on mindful awareness and life satisfaction of adolescents. Journal of Psychosocial Research, 12, 59-70.

Bastounis, A., Callaghan, P., Banerjee, A., \& Michail, M. (2016). The effectiveness of the Penn Resiliency Programme (PRP) and its adapted versions in reducing depression and anxiety and improving explanatory style: a systematic review and meta-analysis. Journal of Adolescent Health, 52, 37-48.

Bluth, K., Roberson, P. N. E., \& Gaylord, S. A. (2015). A pilot study of a mindfulness intervention for adolescents and the potential role of self-compassion in reducing stress. Explore, 11, 292-295.

Bluth, K., Campo, R. A., Pruteanu-Malinici, S., Reams, A., Mullarkey, M., \& Broderick, P. C. (2016). A schoolbased mindfulness pilot study for ethnically diverse at-risk adolescents. Mindfulness, 7, 90-104. 
Broderick, P. (2013). Learning to BREATHE. A mindfulness curriculum for adolescents to cultivate emotion regulation, attention, and performance. Oakland: New Harbinger Press.

Brown, K. W., West, A. M., Loverich, T. M., \& Biegel, G. M. (2011). Assessing adolescent mindfulness: validation of an adapted mindful attention awareness scale in adolescent normative and psychiatric populations. Psychological Assessment, 23, 1023-1033.

Brunwasser, S. M., Gillham, J. E., \& Kim, E. S. (2009). A meta-analytic review of the Penn Resiliency Program's effect on depressive symptoms. Journal of Consulting and Clinical Psychology, 77, 1042-1054.

Canale, N., Vieno, A., \& Griffiths, M. D. (2016). The extent and distribution of gambling-related harms and the prevention paradox in a British population survey. Journal of Behavioral Addictions, 5, 204-212.

Derevensky, J., \& Gupta, R. (Eds.). (2004). Gambling problems in youth. The theoretical and applied perspectives. New York: Kluwer Academic Publishers.

Donovan, J. E., Jessor, R., \& Costa, F. M. (1991). Adolescent health behavior and conventionality-unconventionality: an extension of problem-behavior theory. Health Psychology, 10, 52-61.

Dowling, N. A., Merkouris, S. S., Greenwood, C. J., Oldenhof, E., Toumbourou, J. W., \& Youssefa, G. J. (2017). Early risk and protective factors for problem gambling: a systematic review and meta-analysis of longitudinal studies. Clinical Psychology Review, 51, 109-124.

Dray, J., Bowman, J., Campbell, E., Freund, M., Wolfenden, L., Hodder, R. K., et al. (2017). Systematic review of universal resilience-focused interventions targeting child and adolescent mental health in the school setting. Journal of the American Academy of Child \& Adolescent Psychiatry, 56, 813-824.

Fortuna, L. R., Porche, M. V., \& Padilla, A. (2018). A treatment development study of a cognitive and mindfulness-based therapy for adolescents with co-occurring post-traumatic stress and substance use disorder. Psychology and Psychotherapy: Theory, Research and Practice, 91, 42-62.

Galla, B. M. (2016). Within-person changes in mindfulness and self-compassion predict enhanced emotional well-being in healthy, but stressed adolescents. Journal of Adolescence, 49, 204-217.

Gillham, J. E., Brunwasser, S. M., \& Freres, D. R. (2008). Preventing depression in early adolescence: the Penn resiliency program. New York: Guilford Press.

Gioia, G., Isquith, P.K., Guy, S.C., \& Kenworthy, L. (2000). Reviewed by Baron, I.S. Test review: behavior rating inventory of executive function. Child Neuropsychology, 6, 235-238.

Granero, R., Penelo, E., Stinchfield, R., Fernandez-Aranda, F., Savvidou, L. G., Fröberg, F., Aymamí, N., Gómez-Peña, M., Pérez-Serrano, M., del Pino-Gutiérrez, A., Menchón, J. M., \& Jiménez-Murcia, S. (2014). Is pathological gambling moderated by age? Journal of Gambling Studies, 30, 475-492.

Grant, J. E., Potenza, M. N., Weinstein, A., \& Gorelick, D. A. (2010). Introduction to behavioral addictions. American Journal of Drug and Alcohol Abuse, 36, 233-241.

Jayawardene, W. P., Lohrmann, D. K., Erbe, R. G., \& Torabi, M. R. (2017). Review article: effects of preventive online mindfulness interventions on stress and mindfulness: a meta-analysis of randomized controlled trials. Academic Journal, 5, 150-159.

Kieling, C., Baker-Henningham, H., Belfer, M., Conti, G., Ertem, I., Omigbodun, O., Rohde, L. A., Srinath, S., Ulkuer, N., \& Rahman, A. (2011). Child and adolescent mental health worldwide: evidence for action. Lancet, 378, 1515-1525.

Kuby, A., Mclean, N., \& Karina, A. (2015). Validation of the child and adolescent mindfulness measure (CAMM) with non-clinical adolescents. Mindfulness, 6, 1448-1445.

Kuyken, W., Weare, K., Ukoumunne, O., Vicary, R., Motton, N., Burnett, R., \& Huppert, F. (2013). Effectiveness of the mindfulness in schools programme: non-randomised controlled feasibility study. British Journal of Psychiatry, 203, 126e131.

Liddle, I., \& Carter, G. F. A. (2015). Emotional and psychological well-being in children: the development and validation of the Stirling Children's Well-Being Scale. Educational Psychology in Practice, 31, 174-185.

Quach, D., Jastrowski Mano, K., \& Alexander, K. (2016). A randomized controlled trial examining the effect of mindfulness meditation on working memory capacity in adolescents. Journal of Adolescent Health, 58, 489496.

Rose, G. (1992). The strategy of preventive medicine. Cambridge Oxford University Press.

Salmoirago-Blotcher, E., Druker, S., Frisard, C., Dunsiger, S. I., Crawford, S., Meleo-Meyer, F., et al. (2018). Integrating mindfulness training in school health education to promote healthy behaviors in adolescents: feasibility and preliminary effects on exercise and dietary habits. Preventive Medicine Reports, 9, 92-95.

Schonert-Reichl, K. A., \& Lawlor, M. S. (2010). The effects of a mindfulness-based education program on preand early adolescents' well-being and social and emotional competence. Mindfulness, 1, 137-151.

Shomaker, L. B., Bruggin, S., Pivarunas, B., Skoranski, A., Foss, J., Chaffin, E., \& Bell, C. (2017). Pilot randomized controlled trial of a mindfulness-based group intervention in adolescent girls at risk for type 2 diabetes with depressive symptoms. Complementary Therapy and Medicine, 32, 66-74.

Shonin, E., Van Gordon, W., \& Griffiths, M. D. (2012). The health benefits of mindfulness-based interventions for children and adolescents. Education and Health, 30, 94-97. 
Shonin, E., Van Gordon, W., \& Griffiths, M. D. (2014a). Cognitive Behavioral Therapy (CBT) and Meditation Awareness Training (MAT) for the treatment of co-occurring schizophrenia with pathological gambling: a case study. International Journal of Mental Health and Addiction, 12, 181-196.

Shonin, E., Van Gordon, W., \& Griffiths, M. D. (2014b). Practical tips for teaching mindfulness to school-aged children. Education and Health, 32, 30-33.

Shonin, E., Van Gordon, W., \& Griffiths, M. D. (2016). Ontological addiction: classification, etiology, and treatment. Mindfulness, 7, 660-671.

Sibinga, E. M., Perry-Parrish, C., Chung, S., Johnson, S. B., Smith, M., \& Ellen, J. M. (2013). School-based mindfulness instruction for urban male youth: a small randomized controlled trial. Preventive Medicine, 57, 799-801.

Van Gordon, W., Shonin, E., Sumich, A., Sundin, E., \& Griffiths, M. D. (2014). Meditation Awareness Training (MAT) for psychological wellbeing in a sub-clinical sample of university students: a controlled pilot study. Mindfulness, 5, 381-391.

Van Gordon, W., Shonin, E., \& Griffiths, M. D. (2015). Towards a second-generation of mindfulness-based interventions. Australian and New Zealand Journal of Psychiatry, 49, 591-593.

Van Gordon, W., Shonin, E., \& Griffiths, M. D. (2016). Meditation awareness training for the treatment of sex addiction: a case study. Journal of Behavioral Addictions, 5, 363-372.

Van Gordon, W., Shonin, E., \& Garcia-Campayo. (2017). Are there adverse effects associated with mindfulness? Australian and New Zealand Journal of Psychiatry, 51, 977-979.

Van Gordon, W., Shonin, E., Diouri, S., Garcia-Campayo, J., Kotera, Y., \& Griffiths, M. D. (2018). Ontological Addiction theory: attachment to me, mine, and I. Journal of Behavioral Addictions, Advance Online Publication. https://doi.org/10.1556/2006.7.2018.45.

Weisz, J. R., Sandler, I. N., Durlak, J. A., \& Anton, B. S. (2005). Promoting and protecting youth mental health through evidence-based prevention and treatment. American Psychologist, 60, 628-648.

Windle, G. (2011). What is resilience? A review and concept analysis. Reviews in Clinical Gerontology, 21, 152169.

World Health Organization. (2012). Mapping actions of nongovernmental organizations and other international development organizations. Online at http://apps.who.int/iris/bitstream/handle/10665/44875 /9789241503648_eng.pdf;jsessionid=C2E61168463EF95016D60482AEEAAC91?sequence=1. Accessed 22 Aug 2018.

World Health Organization. (n.d.). Child and adolescent mental health. Online at http://www.who.int/mental health/maternal-child/child_adolescent/en/ Accessed 22 Aug 2018.

Zoogman, S., Goldberg, S., Hoyt, W., \& Miller, L. (2014). Mindfulness interventions with youth: a metaanalysis. Mindfulness, 6, 290-302.

\section{Affiliations}

\section{Supakyada Sapthiang ${ }^{1} \cdot$ William Van Gordon ${ }^{2} \cdot$ Edo Shonin $^{3}$}

1 Public Health Department, University of Essex, 6 Grace Street, Leeds, West Yorkshire LS1 2RP, UK

2 Centre for Psychological Research, University of Derby, Kedleston Road, Derby, Derbyshire DE22 1GB, UK

3 Awake to Wisdom Centre for Meditation and Mindfulness Research, Ragusa, Italy 